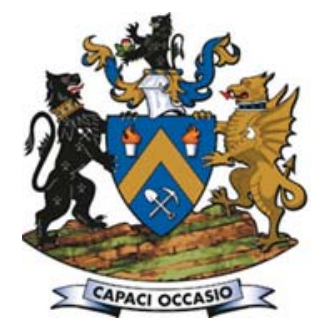

\title{
Spark plasma sintering (SPS) - an advanced sintering technique for structural nanocomposite materials
}

\author{
by W.R. Matizamhuka*
}

\section{Synopsis}

The consolidation of nano-sized composite materials presents a challenge using conventional hot pressing methods. Spark plasma sintering (SPS) technology has shown great promise in the successful sintering of nanoreinforced composite materials. This qualitative review seeks to impart knowledge gathered, and progress made over the years on the consolidation of nanocomposite materials using SPS technology. The review is aimed at introducing this technology to the South African science and engineering community. Emphasis is on improving the mechanical properties of structural ceramic nanocomposite materials, which over the years have shown great promise in a wide range of applications, including transport, energy, mining, and the environment. Although success has been achieved within the laboratory for research purposes, there are still great opportunities to commercialize the technology for the production of larger components with more complex shapes.

\section{Keywords}

ceramic nanocomposites, structural materials, spark plasma sintering, fracture toughness, ceramic matrix composites.

\section{Introduction}

Since the pioneering work of Niihara and Nakahira (1991) over a decade ago there have been extensive attempts to harness the potential of nanostructural metals, ceramics, and composites in a number of applications (Niihara and Nakahira, 1991; Selaho et al., 1997; Sekino and Niihara, 1995; Khalil, 2012; Aalund, 2008). It is generally realized that reducing the grain size of materials to nanoscale offers a significant improvement in properties. Attempts to synthesize nanostructured compacts by conventional sintering methods have not succeeded owing to the uncontrollable high rates of grain growth driven by long dwelling times at the sintering temperatures and large powder surface areas (Sergueeva et al., 2009; Gua, Khora, and Chieng, 2004; Tang et al., 2009). Following the development of spark plasma sintering (SPS) technology, it is now possible to process nanocrystalline materials with controlled grain growth. SPS, also referred to as the field-assisted sintering technique (FAST) or pulsed electric current sintering (PECS), was developed with the aim of improving on the well-established hot pressing (HP) technology (Kessel and Hennicke, 2007;
Suarez et al., 2013; Jiang et al., 2007; Park, Chung, and Kim, 2006; Elissalde, Maglione, and Estournes, 2007; Borodianska et al., 2009). It offers rapid densification, with minimal grain growth, of a wide range of powders which include ceramics, polymers, composites, and metallic-based (Niihara and Nakahira, 1991; Selaho et al., 1997; Sekino and Niihara, 1995; Khalil, 2012; Aalund, 2008). Densification is attained within minutes compared to hours with conventional hot pressing technology (Kessel and Hennicke, 2007; Suarez et al., 2013). This ingenious technique enables homogeneous volumetric heating of both the die set and the specimen, mainly by means of a low-voltage large-pulse current (Joule heating) (Khalil, 2012; Sergueeva et al., 2009; Kessel and Hennicke, 2007; Suarez et al., 2013). Furthermore, the heating power is dissipated at the contact points of the powder particles where energy is required for sintering, which results in improved bonding between the particles (Khalil, 2012). This is a result of the combined effects of rapid heating, pressure application, and the possibility of powder surface cleaning induced by the low-voltage large-pulse current momentarily generated during operation (Khalil, 2012; Aalund, 2008). Conversely, in hot pressing a lot of heat is wasted in an attempt to heat up the whole volume of space from which the specimen indirectly receives heat. Thus SPS is capable of achieving nearly $100 \%$ theoretical density in most materials without the use of binders, and higher purity materials through the vapourization of impurities in the voids between powder particles (Khali, 2012; Aalund, 2008; Rajeswari et al. 2010; Kessel et al., 2009).

* Vaal University of Technology, Department of Metallurgical Engineering, Vanderbijlpark, South Africa.

(C) The Southern African Institute of Mining and Metallurgy, 2016. ISSN 2225-6253. Paper received Sep. 2014; revised paper received Dec. 2015. 


\section{Spark plasma sintering (SPS) — an advanced sintering technique}

The main drawbacks that are usually cited include the limited sample size, shape complexity, and the cost of equipment. In fact, SPS technology has not been commercialized on the African continent as yet.

This paper seeks to review the successes achieved and, more importantly, to introduce the technology to the South African science and engineering community and the rest of Africa. As of 2014, the number of installed SPS machines in the world was estimated at 1750, two of which are installed in South African universities for research purposes (Guillon et al., 2014). It is the author's hope that such knowledge will be valuable to the manufacturing and mining sectors, especially in the manufacture of hard components for machining and drilling purposes

\section{Working principle of SPS}

SPS was first investigated and patented in 1906 (Bloxam, 1906) for the consolidation of powders (Grasso, Sakka, and Maizza, 2009; Oru et al., 2009; Inoue, 1966). It was further developed in the mid-1980s to 1990s to improve on the sintering capabilities of the then-existing conventional sintering technologies (Khalil, 2012; Grasso, Sakka, and Maizza, 2009; Oru et al., 2009; Bloxam, 1906).The basic configuration of a SPS set-up is shown in Figure 1. It consists of a uniaxial pressing device in the form of specially designed graphite punches which also serve as electrodes, a watercooled reaction chamber, a vacuum/air/argon gas atmosphere control mechanism, a pulsed DC generator, and position, temperature, and pressure regulating systems connected to an external computer with appropriate software (Khalil, 2012; Aalund, 2008; Sergueeva et al., 2009; Kessel and Hennicke, 2007; Suarez et al., 2010).

The machine makes use of low voltages (typically $<10 \mathrm{~V}$ ) to produce high currents (typically 1-10 kA). This is enabled by the good electrical conductivity of the tooling materials (Guillon et al., 2014). Heating rates of up to $1000^{\circ} \mathrm{C} / \mathrm{min}$ have been reported, making it possible to sinter within very short durations thus saving on energy costs (Suarez et al., 2010). To enhance the densification process, loads of typically $50-250 \mathrm{kN}$ have been used under vacuum or

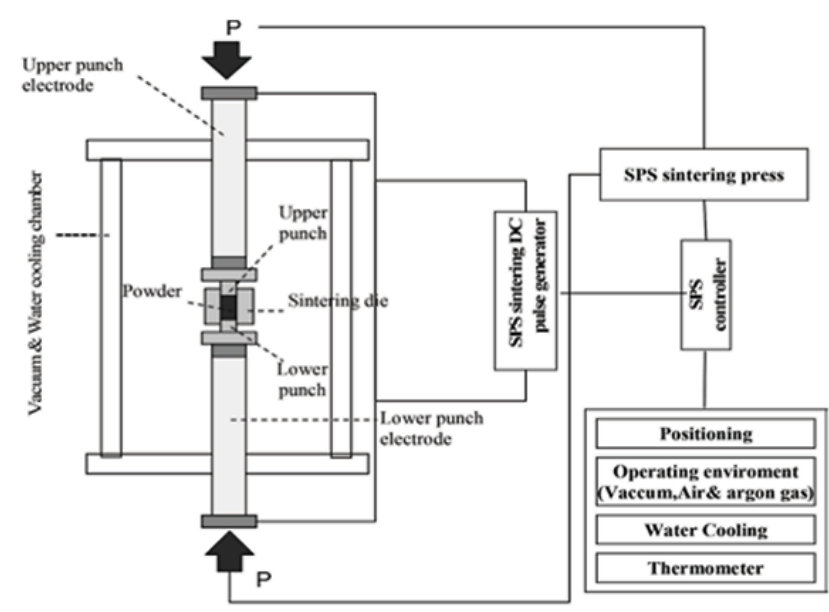

Figure 1-Basic configuration of the spark plasma sintering (SPS) machine (Chen et al., 2005) protective gas at atmospheric pressure (Guillon et al., 2014). The maximum temperature achieved using graphite tools is up to $2400^{\circ} \mathrm{C}$, with standard cooling rates from $150^{\circ} \mathrm{C} / \mathrm{min}$ up to $400^{\circ} \mathrm{C} / \mathrm{min}$ under additional active gas cooling (Guillon et al., 2014). The majority of SPS equipment that has been produced since the early 1990s is based on ON-OFF pulsed DC current technology (Guillon et al., 2014). There is, however, a related technology, developed in 1953, that utilizes AC current and which has been applied in the diamond composite and hard metal industries (Guillon et al., 2014).

The sintering mechanisms involved are a result of three effects - mechanical, thermal, and electrical (Guillon et al., 2014). The mechanical effects are driven primarily by uniaxial pressure applied on the green compact by the pressing tool. Thus the magnitude of the applied stress is limited by the high-temperature fracture strength of the pressing tool and loading system (100-150 MPa for graphite) (Guillon et al., 2014). This implies that high-pressure conditions will require more expensive tooling such as $\mathrm{Si}_{3} \mathrm{~N}_{4}$ or WC, which are more creep resistant, tougher, and more expensive than graphite (Anselmi-Tamburini, Garay, and Munir, 2006; Grasso et al., 2013). Pressure-assisted sintering promotes rearrangement of particles and increases packing efficiency at low temperatures, thus reducing pore size and improving the sintered density (Guillon et al., 2014). However, it should be noted that although grain growth can be significantly delayed under pressure, it is not totally suppressed. At elevated temperatures additional densification mechanisms may be enhanced through power law creep (i.e. materials become softer at higher temperatures). Thus thermal effects play a crucial role in the whole process. The fast heating rates tend to enhance densification while retarding microstructure coarsening due to the short time required to reach sintering temperature. The fast heating rates and short sintering times also minimize interaction between the sample and the graphite tool, thus reducing contamination for materials that are reactive (Guillon et al., 2014). The effects of microscopic thermal gradients are normally negligible for finer grain sizes. These are thought to induce some driving force for diffusion through local temperature differences between particle neck and centre, a phenomenon referred to as Ludwig-Soret thermal diffusion (Guillon et al., 2014). This is, however, strongly dependent on the physical properties, size of particles, and nature of grain boundaries and constituents (Holland et al., 2012). In SPS, macroscopic thermal gradients are almost nonexistent owing to the high heating rates (Suarez et al., 2010).

A comparison of temperature profiles obtained from simulation clearly reveals that small thermal gradients are generated at the high heating rates in SPS compared to conventional sintering methods (Suarez et al., 2013). This explains why conventional sintering requires moderate heating rates and long dwell times to achieve reasonable homogeneity (Rajeswari et al., 2010; Kessel et al., 2009). Figure 2 clearly shows there is a much smaller temperature difference, $\Delta T$, between the edge $\left(T_{A}\right)$ and centre $\left(T_{\mathrm{I}}\right)$ of the SPS sample as opposed to the hot pressed sample (Suarez et al., 2013). Large thermal gradients may result in residual internal stresses and development of microcracks in sintered parts, which is a common occurrence with most conventional 


\section{Spark plasma sintering (SPS) — an advanced sintering technique}
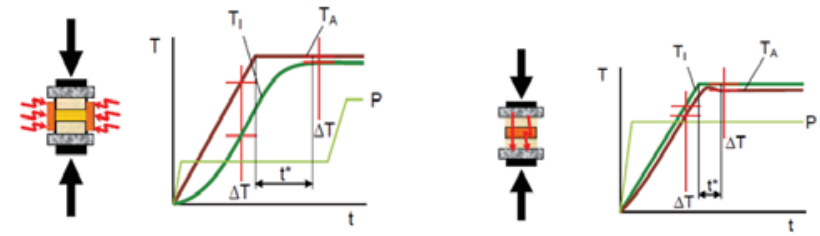

Figure 2-Comparison of the temperature profiles in hot pressing (left) and SPS (right) (Suarez et al., 2013)

sintering methods. In SPS technology the small thermal gradients between the outside and the centre of the part ensure the elimination of residual stresses associated with thermal gradients.

The ON-OFF DC pulse generates electrical effects, which can be differentiated into field and current effects (Guillon et al., 2014; Munir, Quach, and Ohyanagi, 2012; AnselmiTamburini et al., 2012). Thus the resulting microstructure will be influenced by the interaction between the electrical current and the powder green compact (Guillon et al., 2014). The green compact can be electrically conducting or insulating, which results in different electrical effects. For conducting powders the current flows through the powder compact and heat is generated by Joule heating and transmitted to the powder by conduction (Guillon et al., 2014). The current flow through the compact is not homogeneous because of the porous green body. It is thought that a complex network of current paths will form as a result of the initial packing density of the green compact (Guillon et al., 2014). Thus the percolating pulsed current creates fluctuating hot-spots which are characterized by high local current densities at the contact points (Guillon et al., 2014). These hot-spots momentarily induce partial melting, recrystallization, and impurity vapourization during the $\mathrm{ON}$-time and subsequently these liquidized surfaces are bonded by forming 'necks' during the OFF-time; this is enhanced by application of a uniaxial force (Aalund, 2008; Kessel and Hennicke, 2007; Kessel et al., 2009; Tokita, 2013) (Figure 3).

The ongoing compaction increases the density, and the material conductivity rises and the percolation effect tends to fade off with time, leaving 'fingerprints' in the microstructure of the sintered product (Guillon et al., 2014). In the case of nonconductive insulating powders the electrical field normally effects densification through grain boundary migration and matter transport (Raj, Cologna, and Francis 2011; Antolovich and Conrad, 2004). However, this effect is normally observed at much higher voltages in SPS, which implies that the mechanisms through which nonconductive powders sinter are still not well understood (Guillon et al., 2014).

The sintering atmosphere plays a crucial role in the diffusivity and defect structure of the sintering material (Guillon et al., 2014). This means that the densification kinetics, phase stability, stoichiometry, and grain growth are affected by the sintering atmosphere (Varela, Whittemore, and Longo, 1990; Recnik et al., 1994). In general, gas atmospheres have several effects. The adsorption of certain gaseous species can effectively promote reduction in the surface energy of particles, which in turn modifies the thermodynamic driving force for surface reduction and sintering (Guillon et al., 2014). On the other hand, certain gaseous species with low solubility and diffusivity in certain powders can be entrapped in closed pores and oppose the sintering mechanisms due to pressure build-up (Yoon, Chin, and Kang, 2008). Vacuum atmospheres or the presence of certain gas species can promote the vapourization of sintering material, which can lead to a change in stoichiometry/composition or the formation of defects (Guillon et al., 2014).

It is noteworthy, though, that according to the theories described above, the heat generated during SPS sintering is concentrated primarily on the particle surfaces and particle growth is limited partially by the speed of the process, and also the fact that only the surface temperature of the particles rises rapidly (Aalund, 2008).

Although the appearance of thermal plasma in SPS remains controversial, SPS sintering technology has been verified experimentally and the consolidation of powders is greatly enhanced with minimal grain growth (Sergueeva et al., 2009; Chen et al., 2005; Fang, 2010; Anselmi-Tamburini, Garay, and Mumir, 2005). The short durations and relatively lower homologous temperatures involved ensure tight control over grain growth and microstructure, which makes SPS more suitable and attractive for the development of nanocrystalline materials with appreciable grain homogeneity.

\section{Sintering of nanocomposite materials}

Nanostructural materials are more attractive compared to their micrometric counterparts due to their superior mechanical and functional properties. Maglia, Tredici, and Anselmi-Tamburini (2013) have shown that the functional properties such as electrical conductivity, thermal conductivity, and piezoelectric and ferroelectric properties can be directly changed by a nanometric grain structure within a crystallite size below $10 \mathrm{~nm}$. Improved mechanical properties cited include hardness, fracture toughness, wear, enhanced superplasticity, and superior strength (Niihara and Nakahira, 1991; Selaho et al., 1997; Sekino and Niihara, 1995; Sergueeva et al., 2009; Bloxam, 1906; Omori, 2000; Uraiwan et al., 2005; Golla and Basu, 2014). Although advanced ceramics have shown great potential in a wide range of fields (transport, energy, health, environment) owing to their attractive properties (low density, chemical inertness, high strength, high hardness, and high temperature capability) their application is still quite limited, especially under loadbearing conditions, because of their brittle nature (Zhan et al., 2003). As such, some research efforts have been directed towards improving properties such as fracture toughness of

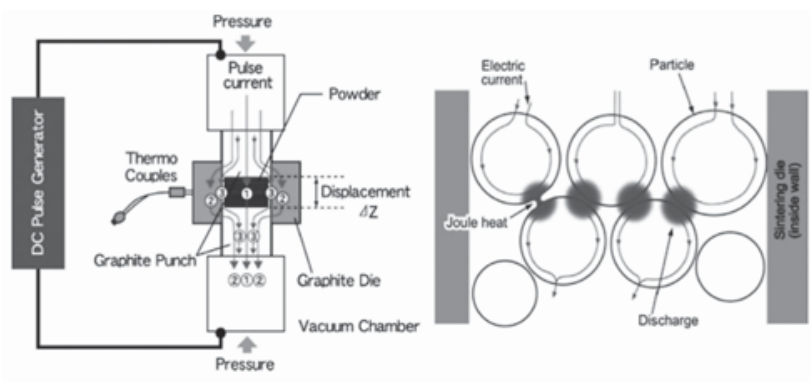

Figure 3-An illustration of the ON-OFF DC pulsed current path and pulsed current flow through powder particles (Chen et al., 2005) 


\section{Spark plasma sintering (SPS) — an advanced sintering technique}

structural ceramics by reinforcing with nano-sized secondary phases (particulate or fibres) (Sekino and Niihara, 1995; Golla and Basu, 2014; Zhan et al., 2003; Basu and Balani, 2011; Mukhopadhyay and Basu, 2007; Niihara and Suzuki, 1999). The basic aim is minimization of grain growth through grain boundary pinning and the introduction of stresses opposing grain growth emanating from the thermal mismatch between the matrix and the dispersed secondary particles (Golla and Basu, 2014; Zhan et al., 2003; Basu and Balani, 2011; Mukhopadhyay and Basu, 2007; Niihara and Suzuki, 1999). It has been observed in previous studies that the fracture toughness of nanocomposite ceramics is improved if the dispersed particles are nano-sized (Golla and Basu, 2014; Zhan et al., 2003; Basu and Balani, 2011; Mukhopadhyay and Basu, 2007; Niihara and Suzuki, 1999). Attempts to obtain nanostructured compacts using conventional sintering methods have not resulted in attractive properties owing to the failure to maintain nano-sized microstructures during the sintering process (Sergueeva et al., 2009). Furthermore, the successful densification of nanopowders is directly influenced by the quality of the initial nanopowder. Most poor-quality nanopowders are highly agglomerated, which makes them very difficult to densify owing to the large macropores that are generated between the agglomerates during sintering. This demands higher sintering temperatures or longer sintering times to break the agglomerates, thus presenting a challenge in controlling the grain growth which normally results in microstructural inhomogenities.

In general, the mechanisms that promote sintering, such as increased temperature and reduced grain size, also accelerate grain growth, thus making it difficult to isolate the two effects. In the last two decades several strategies have been utilized to suppress grain growth during sintering (Maglia, Tredici, and Anselmi-Tamburini, 2013). One such approach is the use of an insoluble second phase, which minimizes grain boundary mobility through grain boundary pinning and stresses that oppose crack propagation. An alternative method is the control of the heating cycle or the use of pressure (Maglia, Tredici, and Anselmi-Tamburini, 2013). This involves fast initial heating rates followed by slower heating rates at high temperatures, thus promoting densification at higher temperatures and reducing time spent at lower temperatures where non-densification processes dominate (e.g. surface diffusion). This is sometimes referred to as the two-step sintering (TSS) cycle. However, the main challenge in using fast heating rates is the generation of thermal inhomogeneities with nonconducting powders. Furthermore, full control of grain size well below $50 \mathrm{~nm}$ is not possible by control of the heating cycle alone. The use of pressure in the sintering of nanocomposites greatly enhances the densification process. This is achieved by inducing nanoparticle rearrangement, particle deformation and sliding, and finally pore shrinkage (Maglia, Tredici, and AnselmiTamburini, 2013). However, the applied pressure may also act as a driving force for grain growth if long sintering times are used (Maglia, Tredici, and Anselmi-Tamburini, 2013). This is the case when using hot pressing techniques.

\section{Properties of structural nanocomposites}

The concept of structural nanocomposite ceramics was proposed by Niihara and Nakahira (1991) over two decades ago. The greatest attraction associated with nanocomposite ceramics is the improved fracture toughness, which makes them appropriate for load-bearing applications. The concept involves incorporating energy-dissipating second phases in various forms (particles, whiskers, platelets etc.) that are effective in crack deflection or crack bridging, which in turn hinders further crack propagation (Zhan et al., 1996; Lawn, 1998; Yamamoto et al., 2008). Furthermore, the use of nanosized particles ensures a reduction in the flaw size, which also contributes to improving the fracture toughness through increased grain boundary density (Zhan et al., 1996; Lawn, 1998; Yamamoto et al., 2008). This means that more energy is required for a crack to move through the matrix (Zhan et al., 1996; Lawn, 1998; Yamamoto et al., 2008). Thermal expansion mismatch between dispersed particles and the matrix is thought to cause residual stresses within and around the particles when composites cool down after sintering (Zhan et al., 1996; Lawn, 1998; Yamamoto et al., 2008). It is expected that the tensile stress component can induce radial microcracks in the matrix around each particle, which improves the fracture toughness through crack deflection (Yamamoto et al., 2008). This, however, requires that the matrix exhibits a lower thermal expansion than the second-phase particles (Yamamoto et al., 2008). This is similar to bone structure, which is full of microscopic cracks that are responsible for the deflection of advancing cracks from the path of or direction of maximum tensile stress (Ritchie, Buehler, and Hansma, 2009). This makes bone remarkably resistant to fracture.

Previous studies have proved that the mean grain size and distribution of the secondary particles is critical as this affects the location of the particulate in the matrix (Zhan et al., 2003; Sciti, Vicens, and Bellosi, 2002). Sciti, Vicens, and Bellosi (2002) showed that SiC particles of $<150 \mathrm{~nm}$ in an $\mathrm{Al}_{2} \mathrm{O}_{3}$ matrix tend to detach from advancing grain boundaries and are situated within the matrix, whereas larger particles are found mainly in intergranular positions. Uraiwan et al. (2005) proposed three basic nanocomposite microstructures: intragranular type, intergranular type, and nano-nano type. In the case of intergranular type, particles are dispersed within the grain boundaries, hindering crack extension along grain boundaries through the strong bonding between the matrix and the dispersion interface (Borsa et al., 1994), whereas an intragranular-type microstructure causes crack deflection and impediment along the matrix grains, thus resulting in significant toughening. The most attractive microstructure is the one consisting of dispersed particles embedded within the matrix grains (intra-type) (Zhan et al., 2003). This is typically found in nanocomposites with a low volume fraction of secondary phase; such structures have better sinterability (Zhan et al., 2003).

In principle, toughening mechanisms can be categorized into two types: intrinsic and extrinsic. Intrinsic mechanisms operate ahead of a crack tip and are related primarily to plasticity, i.e. enlargement of the plastic zone, which is effective against both crack initiation and propagation (Ritchie, 2011). This is the primary source of toughening in ductile materials and is ineffective with brittle materials. Conversely, extrinsic toughening acts primarily on the wake of the crack to shield local stresses and strains at the crack 


\section{Spark plasma sintering (SPS) — an advanced sintering technique}

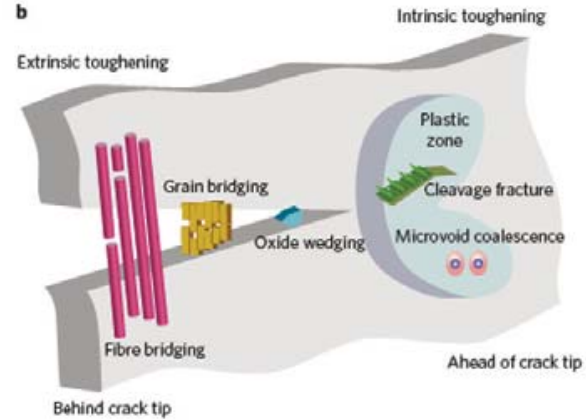

Figure 4-Schematic representation of extrinsic and intrinsic toughening mechanisms (Ritchie, 2011)

tip. Effectively, extrinsic toughening is usually associated with processes behind a crack tip and there has to be a crack for these processes to operate, thus they have no effect on crack initiation (Ritchie, 2011). There are a variety of microstructural mechanisms utilized to effect extrinsic toughening, including crack bridging by unbroken fibres or ductile phase in composites, friction interlocking of grains during intergranular fracture in monolithic ceramics, meandering and crack surface sliding, and shielding and microcracking in transformation-toughened ceramics.

The reader is referred to the work by Niihara and Nakahira (1991) for further details on nanocomposite modifications. The success of achieving the above is largely governed by the powder characteristics such as particle size, degree of agglomeration, and reactivity.

\section{Processing of nanocomposites}

The properties of sintered nanocomposite materials are greatly dependent on the processing route. Powders for nanocomposites have been processed through different methods, which can be classified as solid-state processing (mechanical alloying, laser ablation, evaporation-condensation, and self-propagating high-temperature synthesis (SHS)), gas-phase processing (chemical vapour deposition (CVD), plasma, and laser synthesis), and solution chemistry methods (sol-gel, polymer pyrolysis, and spray drying of solutions) (Tomar, 2008; Maitra, 2014; Borsa and Brook, 1995; Caroll, Sternitzke, and Derby, 1996; Niihara et al., 1989; Shapiro, Todd, and Roberts, 2009; Liu, Zhou, and Hou, 2006; Xu, Nakahira, and Niihara, 1994; Galusek, Sedlacek, and Riedel, 2007). Powder processing routes require powders of high purity to avoid the formation of second phases (Zhan et al., 1996). A typical processing procedure would involve (Zhan et al., 1996):

(i) Selection of raw materials

(ii) Wet mixing

(iii) Drying of slurries

(iv) Consolidation.

The most critical step is the drying process because of the risk of agglomeration (Zhan et al., 1996). Fast drying rates at higher temperatures have been found to result in the formation of hard agglomerates which are detrimental to microstructural uniformity. In such cases every effort is made to control the rate of drying. An alternative method is freeze drying, which provides optimal conditions that suppress the formation of agglomerates and segregation (Walker et al., 1994; Upadhyaya, 2011) Polymer pyrolysis and sol-gel synthesis routes offer attractive alternative procedures that result in better dispersion at an atomic level (Borsa and Brook, 1995; Liu, Zhou, and Hou, 2006; Xu, Nakahira, and Niihara, 1994; Galusek, Sedlacek, and Riedel, 2007). Furthermore, they are cheaper and involve simple procedures for the production of bulk homogeneous nanopowders. The main challenge, however, is that most of the powders produced by solution chemistry methods are amorphous and require a final heat treatment at relatively high temperatures to promote crystallization or removal of organic additives. This normally results in increased grain size and partial consolidation of agglomerates (Maglia, Tredici, and AnselmiTamburini, 2013). Mechanical milling might be required to break these agglomerates as a final step, which may expose the powders to further contamination.

\section{Insights on SPS of structural nanocomposites}

Strictly speaking, the majority of nanocomposites investigated to date are composites with microcrystalline matrices and nanoscale secondary phases (Sergueeva et al., 2009; Tokita, 2013; Golla and Basu, 2014). Very few truly nano-nano composites have been investigated, and this presents a great opportunity to generate property and microstructural data for truly nano-nano composites using SPS technology. As mentioned earlier, nanocomposite materials possess superior fracture toughness compared to their microcrystalline counterparts. The introduction of a nanoscale second phase is beneficial in two ways (Sergueeva et al., 2009):

(i) Suppresses grain growth of the matrix

(ii) Improves the fracture toughness owing to the thermal mismatch between the matrix and the second phase.

The use of SPS technology preserves the grain size within the nanoscale range due to the fast sintering times and lower sintering temperature in the SPS system. The particle shape and size of the second phase play a crucial role in the determination of the extent of toughening or strengthening in most nanocomposite materials (Sergueeva et al., 2009; Tokita, 2013; Golla and Basu, 2014). A number of technologically important groups of ceramic nanocomposites have been studied to date. Some of the more significant include alumina-based $\left(\mathrm{Al}_{2} \mathrm{O}_{3}-\mathrm{SiC}, \mathrm{Al}_{2} \mathrm{O}_{3}-\mathrm{Si}_{3} \mathrm{~N}_{4}, \mathrm{Al}_{2} \mathrm{O}_{3}-\mathrm{ZrO}_{2}, \mathrm{Al}_{2} \mathrm{O}_{3^{-}}\right.$ graphene, $\mathrm{Al}_{2} \mathrm{O}_{3}$-TiC/TiN, $\mathrm{Al}_{2} \mathrm{O}_{3}$-metallic phase); zirconiabased, $\mathrm{Si}_{3} \mathrm{~N}_{4} / \mathrm{SiC}$, and $\mathrm{Si}_{3} \mathrm{~N}_{4}$-graphene systems. The description that follows is not meant to be exhaustive but to highlight the salient features of some of the most common groups of nanocomposites.

\section{Alumina-based nanocomposites}

Alumina is one of the most widely used ceramic materials owing to its attractive properties, low cost, and less demanding sintering conditions. However, like other ceramic materials, alumina suffers brittle fracture under load-bearing conditions, which limits its application as a load-bearing material. Over the years a number of studies have been dedicated to improving the toughness and strength of alumina ceramics through a number of methods such as: 


\section{Spark plasma sintering (SPS) — an advanced sintering technique}

(i) Dispersing a small amount of a harder phase such as $\mathrm{SiC}, \mathrm{Si}_{3} \mathrm{~N} 4$, and $\mathrm{ZrO}_{2}$

(ii) Dispersing with a ductile phase such as metallic particles $(\mathrm{Cr}, \mathrm{Ni}, \mathrm{Cu})$ or high-strength phases such as carbon nanotubes (CNTs) or graphene nanoplatelets (GNPs) (Sergueeva et al., 2009; Yamamoto et al., 2008; He et al., 2009; Wang and Steven, 1989; Nieto, Lahiri, and Agarwal, 2012; Liu et al., 2012; Chae et al., 2006; Choa et al., 1998; Gao et al., 1999a, $1999 b)$.

The majority of the work has been done on the $\mathrm{Al}_{2} \mathrm{O}_{3} / \mathrm{SiC}$ system (Golla and Basu, 2014; Yamamoto et al., 2008; Chae et al., 2006; Choa et al., 1998; Gao et al., 1999a, 1999b). Since the pioneering work of Niihara (1991) a number of studies have been undertaken to test the properties of SiCreinforced $\mathrm{Al}_{2} \mathrm{O}_{3}$ nanocomposites. Niihara and Nakahira reported an improvement in fracture toughness from $3 \mathrm{MPa}$.m 0.5 for monolithic $\mathrm{Al}_{2} \mathrm{O}_{3}$ to $4.7 \mathrm{MPa} \cdot \mathrm{m}^{0.5}$ for $\mathrm{Al}_{2} \mathrm{O}_{3}-5$ vol\% $\mathrm{SiC}$, and a strength increase of $300 \%$ from $350 \mathrm{MPa}$ to $1000 \mathrm{MPa}$. Current studies have shown that nano-SiC reinforcement in the submicrometre $\mathrm{Al}_{2} \mathrm{O}_{3}$ matrix imparts a substantial improvement in strength with a modest increase in the fracture toughness (Golla and Basu, 2014; Yamamoto et al., 2008; He et al., 2009; Wang and Steven, 1989; Nieto, Lahiri, and Agarwal, 2012; Liu et al., 2012; Chae et al., 2006; Choa et al., 1998; Gao et al., 1999a, 1999b; Taya et al., 1990). One of the motivations for interest in SiC-reinforced composites is the toughening mechanism associated with the composites, referred to as residual stress toughening. This phenomenon is a result of differences in thermoelastic properties between the matrix and the dispersed phase (Sergueeva et al., 2009; Anya, 1999). Stress in the matrix is generated when $\alpha_{p}>\alpha_{m}$ (where $\alpha_{p}$ and $\alpha_{m}$ are the thermal expansion coefficients of the particulate and matrix respectively), such that there are compressive residual stresses on the dispersed particles which are effective in crack deflection (Anya, 1999). Generally, the larger the difference in the thermal coefficients the more pronounced the stress effect. A summary of thermoelastic properties of some of the most commonly used ceramic materials follows.

One of the early investigations on the successful SPS of $\mathrm{Al}_{2} \mathrm{O}_{3}$-SiC composites was carried out by Choa et al. (1998). In this study, finely dispersed SiC particles $(200 \mathrm{~nm})$ were found within the $\mathrm{Al}_{2} \mathrm{O}_{3}$ grains and the composites exhibited a fracture toughness of 5.8 MPa.m.5 and strength of $1200 \mathrm{MPa}$ compared to $3.2 \mathrm{MPa}^{0.5}$ and $700 \mathrm{MPa}$ respectively for monolithic $\mathrm{Al}_{2} \mathrm{O}_{3}$. In a separate study Chae et al. (2006) compared the sintering dynamics of $\mathrm{Al}_{2} \mathrm{O}_{3}$-SiC composites containing $5 \mathrm{vol} \%$ and $20 \mathrm{vol} \% \mathrm{SiC}$ under hot pressing and SPS conditions. Generally, the presence of SiC reduced the rate of grain growth seven-fold and the rate of densification was higher under SPS compaction compared to hot pressing. A moderate increase in fracture toughness $3.6 \mathrm{MPa} \mathrm{m}^{0.5}$ and flexural strength of $812 \mathrm{MPa}$ was obtained for $\mathrm{Al}_{2} \mathrm{O}_{3}$ 20 vol\% SiC, lower than obtained by Niihara et al. (1989). Similar microstructural observations were claimed by Gao et al. (1999a) for $\mathrm{Al}_{2} \mathrm{O}_{3}-5 \mathrm{vol} \% \mathrm{SiC}$ densified at $1500^{\circ} \mathrm{C}$ for 3 minutes. A fracture toughness value of $4 \mathrm{MPa} . \mathrm{m}^{0.5}$ was obtained, and the microstructures revealed that the $\mathrm{SiC}$ particles were located mainly inside the $\mathrm{Al}_{2} \mathrm{O}_{3}$ grains with the fracture mode being mainly transgranular. The use of certain ductile metallic phases has proved effective in the toughening of alumina ceramics because the ductile phase can absorb and dissipate stress by elastic and plastic deformation. The widely accepted toughening mechanism is through crack bridging by ductile ligaments in the crack wake (Sergueeva et al., 2009; Anya, 1999; Sigl, Makaga, and Dalgeish, 1988). A fracture toughness of $7 \mathrm{MPa} . \mathrm{m}^{0.5}$ was recorded for an $\mathrm{Al}_{2} \mathrm{O}_{3}$ $10 \mathrm{vol} \% \mathrm{Nb}$ nanocomposite sintered at $1100^{\circ} \mathrm{C}$ for 3 minutess by SPS (Suarez et al., 2013; Volceanov et al., 2007). This is well above that of the monolithic $\mathrm{Al}_{2} \mathrm{O}_{3}$ phase ( $3 \mathrm{MPa} \cdot \mathrm{m}^{0.5}$ ); however, the major disadvantage with metallic reinforcements is their limited application range and reduced hardness values in the matrix. At high temperatures the metallic phases are prone to softening and undergo plastic deformation, which leads to degradation of mechanical properties.

Another concept of toughening alumina involves dispersing with zirconia nanoparticles, which has been practiced for over two decades. This group of nanocomposites is commonly referred to as zirconia-toughened alumina (ZTA). The microstructures of ZTA are characterized by $\mathrm{ZrO}_{2}$ particles finely dispersed in an $\mathrm{Al}_{2} \mathrm{O}_{3}$ matrix, with toughening being induced mainly through stress-induced transformation and microcrack toughening. The stress-induced transformation mechanism is associated with volumetric expansion and shear strains as $\mathrm{ZrO}_{2}$ transforms from tetragonal to monoclinic structure on cooling (Volceanov et al., 2007; Claussen, 1976; Lange, 1982; Claussen, Steeb, and Pabst, 1977; McMeeking and Evans, 1982; Evans and Cannon, 1986; Claussen, and Ruhle, 1981). Toughness values of $>12 \mathrm{MPa} . \mathrm{m}^{0.5}$ have been obtained, compared to $3 \mathrm{MPa} \cdot \mathrm{m}^{0.5}$ for monolithic $\mathrm{Al}_{2} \mathrm{O}_{3}$ (Wang and Stevens, 1989). Again, this group of composites has a limited temperate range of application, with most of the toughening being lost at elevated temperatures as $\mathrm{ZrO}_{2}$ transforms back to the tetragonal structure.

Although several attempts have been made to improve the mechanical properties of $\mathrm{Al}_{2} \mathrm{O}_{3}$ matrices there are still challenges in the processing and homogenous dispersal of the nano-powders in the matrix. Most of the composites produced by SPS to date have been widely accepted as well sintered, although the mechanical properties are still inconsistent.

\section{Zirconia-based nanocomposites}

Tetragonal $\mathrm{ZrO}_{2}$ polycrystals (TZP) possess excellent bending strengths (approx. $1000 \mathrm{MPa}$ ) and fracture toughness values (>10 MPa.m0.5) compared to other monolithic ceramics (Anjali et al., 2012). This emanates from the induced transformation of tetragonal zirconia $\left(\mathrm{t}-\mathrm{ZrO}_{2}\right)$ to the monoclinic zirconia $\left(\mathrm{m}-\mathrm{ZrO}_{2}\right)$ phase, which is associated with a volumetric expansion and formation of microcracks in the stress field of a propagating crack - a phenomenon known as transformation toughening (Anjali et al., 2012; Sternitzke, 1997). However, $\mathrm{ZrO}_{2}$ polycrystals have relatively lower hardness values ( $<12 \mathrm{GPa}$ ), which tend to limit their range of application, and also the stress-induced transformation toughening mechanism of TZP degrades at higher temperatures (Sternitzke, 1997). Thus there is great interest in improving the hardness and high-temperature toughness of $\mathrm{ZrO}_{2}$ ceramics, mostly through incorporating carbide inclusions with superior hardness such as TiC, SiC, and WC, 


\section{Spark plasma sintering (SPS) — an advanced sintering technique}

borides $\left(\mathrm{ZrB}_{2}\right)$, and nitrides (TiN). The second phases used have lower coefficients of thermal expansion, which induces residual compressive stress on the second phase (Table I) when the composite cools down. However, the principle of residual stress toughening requires that the matrix exhibits a lower thermal expansion than the incorporated particles. In the Y-TZP/TiC system, for example, the opposite applies, thus the toughening mechanism is likely to be crack deflection/ bowing with less microcracking (Sternitzke, 1997). The interaction of the primary crack front with pre-existing and/or transformation-induced microcracks will only increase toughening (Zhan et al., 1996). Yittria-stabilized $\mathrm{ZrO}_{2}$ containing $40 \mathrm{vol} \%$ nano-WC sintered by SPS at $1450^{\circ} \mathrm{C}$ at a pressure of $60 \mathrm{MPa}$ was found to possess enhanced flexural strength of $2000 \mathrm{MPa}$, hardness of $16.2 \mathrm{GPa}$, and fracture toughness of 6.9 MPa.mo.5 (Golla and Basu, 2014). In another study, the mechanical properties of $\mathrm{ZrO}_{2}-30 \mathrm{vol} \%$ $\mathrm{ZrB}_{2}$ obtained under SPS $\left(1200^{\circ} \mathrm{C}, 5\right.$ minutes' holding time, and a heating rate of $600 \mathrm{~K} / \mathrm{min}$ ) showed a moderate improvement in hardness (12-14 GPa) and fracture toughness (6-11 MPa) with transformation toughening. Importantly, the grain size and presence of transformation toughening have been found to play a critical role in enhancing the mechanical properties of $\mathrm{ZrO}_{2}$-based nanocomposites (Golla and Basu, 2014).

Vanmeensel et al. (2007) observed a decrease in hardness and fracture toughness of $\mathrm{ZrO}_{2}$-TiN composites (sintered at $1500^{\circ} \mathrm{C}, 2$ minutes, $56 \mathrm{MPa}$ ) with increasing TiN content. The TZP-35 vol\% TiN had the highest fracture toughness ( $7.6 \pm 0.3 \mathrm{MP} . \mathrm{am}^{0.5}$ ) with $41 \%$ of the $\mathrm{ZrO}_{2}$ transformed in the matrix, and a hardness of $13.19 \mathrm{GPa}$ was obtained. This is a modest improvement in comparison to monolithic TZP.

\section{$\mathrm{Si}_{3} \mathrm{~N}_{4}$-SiC nanocomposites}

The nanocomposites of $\mathrm{SiC}-\mathrm{Si}_{3} \mathrm{~N}_{4}$ ceramics are of great technological importance owing to their attractive properties such as high hardness and strength, and excellent creep, oxidation, and corrosion resistance (Niihara, 1991; Sternitzke, 1997). Conventionally, the sintering of SiCreinforced $\mathrm{Si}_{3} \mathrm{~N}_{4}$ composites requires the use of a liquid phase to achieve higher densities owing to the large driving force required for bonding the highly covalent materials (Sternitzke, 1997). SPS has been successfully applied in the synthesis of highly creep-resistant $\mathrm{Si}_{3} \mathrm{~N}_{4}$-SiC composites without the use of a liquid phase (Herrmann et al., 1998). These nanocomposites have enhanced creep resistance and excellent strength in comparison to monolithic $\mathrm{Si}_{3} \mathrm{~N}_{4}$ (Sternitzke, 1997; Herrmann et al., 1998).

\begin{tabular}{|l|c|}
\hline \multicolumn{2}{|l|}{$\begin{array}{l}\text { Table } I \\
\text { Coefficients of thermal expansion }\end{array}$} \\
\hline Materials & Coefficient of thermal expansion $\left(\mathbf{0}-1000^{\circ} \mathbf{C}\right) \mathbf{a}\left(\times 10^{-6} \mathrm{~K}-1\right)$ \\
\hline $\mathrm{Al}_{2} \mathrm{O}_{3}$ & 8.3 \\
$\mathrm{Si}_{3} \mathrm{~N}_{4}$ & 3.2 \\
$\mathrm{TiN}^{\mathrm{N}}$ & 9.4 \\
$\mathrm{SiC}$ & 4.4 \\
$\mathrm{ZrO}_{2}$ & 10.0 \\
$\mathrm{TiC}$ & 7.4 \\
\hline
\end{tabular}

\section{Carbon nanotube (CNT) and graphene nanoplatelet (GNP) reinforced nanocomposites}

Since the report by lijima (1991) on carbon nanotube (CNT) reinforcement there have been a number of studies aimed at mechanical property improvement through CNT-reinforced composites (Yamamoto et al., 2008; Iijima, 1991). The understanding is that CNTs possess high tensile strength (20-100 GPa) and high aspect ratio (>5000), making them suitable for reinforcement applications (Iijima, 1991). Due to their high elasticity they play a critical role in absorbing most of the strain-related energy. The use of CNTs to reinforce ceramics has been motivated by the fibre bridging effect resulting from debonding and sliding resistance, which strengthens the composites and improve fracture toughness (Yamamoto et al., 2008). The commonly accepted mechanisms contributing to improved strength and toughness in CNT-reinforced nanoceramics include crack deflection at the $\mathrm{CNT}$ /ceramic interface, crack bridging by the CNT, and pullout of CNTs on the crack plane (Yamamoto et al., 2008; Sahetat et al., 1999).

In light of the above, a number of CNT-reinforced composites have been studied, and in a number of cases they show some improvement in mechanical properties, especially strength and fracture toughness. Yamamoto et al. (2008) reported a $25 \%$ increase in fracture toughness for a $5 \mathrm{vol} \%$ CNT addition (in the form of multi-walled carbon nanotubes (MWCNTs)) to alumina (Yamamoto et al., 2008; Sahetat et al., 1999). Zhan et al. (2003) obtained a fracture toughness of 9.7 MPa.m 0.5 for an alumina composite reinforced with 10 vol\% SWCN (single-wall carbon nanotubes). This was enabled by the lower sintering temperatures and shorter times required to obtain fully dense materials with SPS compared to conventional sintering methods. Furthermore, a remarkably higher fracture toughness of $13.5 \mathrm{MPa}$.m 0.5 was obtained for an alumina-SWCNT system to which Nb was added as a ductile phase (Baughman, Zakhidov, and de Heer, 2002; Kuntz et al., 2002). The higher fracture toughness is attributed to the more ductile $\mathrm{Nb}$ metallic phase. In another study, the fracture toughness of zirconia-toughened alumina (ZTA) was improved by $44 \%$ by incorporating CNTs (Bocanegra and Echeberria, 2011).

The development of CNT-reinforced composites is still limited by the difficulty in obtaining homogeneous mixtures and the high cost of CNTs (Yamamoto et al., 2008; Dusza et al., 2012). Furthermore, CNTs have a tendency to agglomerate and form 'ropes' and 'bundles', which makes it difficult to homogenously disperse CNTs in the matrix to form adequate interfacial connectivity between the two phases (Yamamoto et al., 2011; Kawano, Takahashi, and Shimada, 2002). This explains the bulk of the disappointing results that have been reported so far. Yamamoto et al. (2011), through electron microscopy studies, observed some form of debonding of MWCNTs from the matrix and recorded a fracture toughness of 4.74 MPa.m 0.5 and a binding strength of $543.8 \mathrm{MPa}$ with $0.9 \mathrm{vol} \%$ MWCNTs in an alumina matrix. This result is not far off from that obtained for the monolithic alumina synthesized under similar conditions (4.37 MPa.mo.5 and 502.3 MPa respectively) (Yamamoto et al., 2011). 


\section{Spark plasma sintering (SPS) — an advanced sintering technique}

Recently there has been wide interest in the fabrication of graphene-reinforced composites as an alternative to CNTs. Graphene is a two-dimensional counterpart of CNTs, consisting of a one-atom thick layer of $\mathrm{C}$ atoms in a honeycomb (the parallel stacked layers found in graphite) (Liu, Yan, and Jiang, 2013; Anon., 2010; Cheng et al., 2011; Geim and Novoselov, 2007; Liao et al., 2010). The motivation for its use is the higher fracture strength in comparison to CNTs for similar type of defects and the easiness of homogeneous dispersion in ceramic matrices (Hirata et al., 2004; Yu et al., 2000). Graphene is normally referred to in the literature as graphene platelets (GPLS), graphene nanosheets (GNS), multi-layer graphene nanosheets (MGN), or graphene nanoplatelets (GNPs) and consists of several layers of graphene with a thickness of 100 $\mathrm{nm}$ (Yoon et al., 2012). Graphene is normally made by micromechanical exfoliation of expanded graphite, chemical processing (Hirata et al., 2004; Yu et al., 2000; Stankovich et al., 2006; Zhan et al., 2003; Jang and Zhamu, 2008), or by subjecting graphite to shear stresses which induce some slipping of the stacked layers, such as in high-energy ball milling (Potts et al., 2011).

Several attempts have been made to sinter GPL-reinforced composites using SPS. Wang and Stevens (1989) reported a $53 \%$ increase in fracture toughness with $\mathrm{Al}_{2} \mathrm{O}_{3}$ containing 2 wt\% GPLs. In a separate study Liu et al. (2012) reported a $40 \%$ increase in fracture toughness with $0.81 \mathrm{vol} \%$ GPL in $\mathrm{Al}_{2} \mathrm{O}_{3}$. In a recent study a $27.20 \%$ improvement in fracture toughness and $30.75 \%$ increase in flexural strength was reported (Liu, Yan, and Jiang, 2013) for an alumina-GPL composite. Walker et al. (2011) prepared $\mathrm{Si}_{3} \mathrm{~N}_{4}-1.5 \mathrm{wt} \% \mathrm{GPL}$ and obtained a fracture toughness of $6.6 \mathrm{MPa} \cdot \mathrm{m}^{0.5}$, which was $136 \%$ higher than the monolithic binderless $\mathrm{Si}_{3} \mathrm{~N}_{4}$ obtained using similar conditions. These studies clearly indicate a significant improvement in fracture toughness and strength for the CNT, GPL-reinforced composites. However, there are still some inconsistencies in the results. The potential for obtaining even better results depends on the ability to process the raw powders more effectively (homogeneous mixing) and minimizing the level of impurities in the composites.

\section{Concluding remarks}

A key target in ceramic research has been the identification and assessment of ways to improve the mechanical properties, especially fracture toughness and flexural strength, which still hinder the wider application of ceramic materials. There is great potential for tailoring the microstructures and improve fracture toughness properties of nanocomposite ceramic materials by utilizing SPS technology. The critical requirements for achieving this goal include control of grain size, particle morphology, particle size distribution, and the volume fraction of the second-phase particles. In most of the reported work the microstructures of the SPSsintered nanocomposites are excellent, but the mechanical properties are still unsatisfactory and inconsistent. It is commonly accepted that nanocomposite structural ceramics have great potential for wider applications from the scientific point of view, but their development at the industrial level is held back due to a number of reasons.
1. The cost of producing bulk nano-scale powders is still prohibitively high

2. The processing technology, especially regarding the homogeneous mixing of nanopowders, is still not well refined.

SPS technology has shown great potential for mitigating some of the problems associated with the densification of nano-scale materials. However, much research is still needed in order to obtain a clear understanding of the fundamental mechanisms of sintering and the effects of the electrical current on mass transport, reactivity, microstructure evolution, and final properties, as well as to enable scale-up to larger specimen dimensions with more flexible geometries. This can be achieved only through closer collaboration between universities, research institutes, and industry.

\section{References}

AALund, R. 2008. Spark plasma sintering. Ceramic Industry Magazine, May.

Anjali, M.C., Biswas, P., ChaKravarty, D., Hareesh, U.S., Rao, Y.S., and Johnson, R. 2012. Low temperature in-situ reaction sintering of zircon: alumina composites trough spark plasma sintering. Science of Sintering, vol. 44 pp. 323-330.

Anonymous. 2010. The rise and rise of graphene. Nature Nanotechnology, vol. 5 , no. 755 . DOI: $10.1038 /$ nnano.2010.224.

Anselmi-Tamburini, U., Sinolo, G., Maglia, F., Tredici, I., Holland, T.B., and MuKHERJEE, A.K. 2012. Field assisted sintering mechanisms. Sintering: Mechanisms of Convention Nanodensification and Field Assisted Processes. Castro, R. and van Benthem, K. (eds.). Springer, Berlin/Heidelberg. Ch.8, pp. 159-193.

Anselmi-Tamburini, U., Garay, J.E., and Mumir, Z.A. 2005. Fundamental investigations on the spark plasma sintering/synthesis process: III. Current effect on reactivity. Materials Science and Engineering A, vol. 407, no. 1-2. pp. 24-30.

AnSElmi-TAmbuRinI, U., GARAY, J.E., and MuniR, Z.A. 2006. Fast low-temperature consolidation of bulk nanometric ceramic materials. Scripta Materialia, vol. 54, no. 3. pp. 823-828.

Antolovich, S.D. and ConRAD, H. 2004. The effects of electric currents and fields on deformation in metals, ceramics, and ionic materials: an interpretive survey. Materials and Manufacturing Processes, vol. 19, no. 4. pp. 587-610.

ANYA, C.C. 1999. Microstructural nature of strengthening and toughening in $\mathrm{Al}_{2} \mathrm{O}_{3} \mathrm{SiC}(\mathrm{p})$ nano-composites. Journal of Materials Science, vol. 34 . pp. 5557-5567.

BASU, B. and BALANI, K. 2011 Advanced Structural Ceramics. Wiley, USA.

BAUghman, R.H., ZAKHIDOv, A.A., and DE HEER, W.A. 2002. Carbon nanotubes the route toward applications. Science, vol. 297. pp. 787-792.

BLoxAM, AG. 1906. Improved manufacture of electric incandescence lamp filaments from tungsten or molybdenum or an alloy thereof. British patent 27,002 .

BoCANEGRA, M.H. and EcheberRIA, J. 2011. A comparison of the effects of multiwall and single-wall carbon nanotube additions on the properties of zirconia toughened alumina composites. Carbon, vol. 49, no. 5 . pp. 1599-1607.

Borodianska, H., Krushinskaya, L., Makarenko, G., SakKa, Y., Uvarova, I., and VASYLKIV, O. 2009. $\mathrm{Si}_{3} \mathrm{~N}_{4}$-TiN nanocomposite by nitration of $\mathrm{TiSi}_{2}$ and consolidation by hot pressing and spark plasma sintering. Journal of Nanoscience and Nanotechnology, vol. 9, no. 11. pp. 6381-6389.

BorsA, C.E. and BRooK, R.J. 1995. Fabrication of $\mathrm{Al}_{2} \mathrm{O}_{3} / \mathrm{SiC}$ nanocomposites using a polymeric precursor for SiC. Ceramic Transactions 51. Ceramic Processing and Science. Hausner, H., Messing, G.L., and Hirano, S-I. (eds.). American Ceramic Society, Westerville OH, USA. pp. 653-57.

Borsa, C.E., Jiao, S., TodD, R.I., and Brooke, R.J. 1994. Processing and properties of $\mathrm{Al}_{2} \mathrm{O}_{3} / \mathrm{SiC}$ nanocomposites. Journal of Microscopy, vol. 177 . pp. 305-312.

CAroll, L., Sternitzke, M., and Derby, B. 1996. Silicon carbide particle size effects in alumina-based nano-composites. Acta Materialia, vol. 44, no. 11. pp. 4543-4552. 


\section{Spark plasma sintering (SPS) — an advanced sintering technique}

Chae, J.H., Kim, K.H., СhoA, Y-H., Matsushita, J-I., Yoon, J-W., and Boshim, K. 2006. Microstructural evolution of $\mathrm{Al}_{2} \mathrm{O}_{3}$-SiC nanocomposites during spark plasma sintering. Journal of Alloys and Compounds, vol. 413, no. $1-2$. pp. 259-264

Chen, W., Anselmi-Tamburini, U., Garay, J.E., Groza, J.R., and Munir, Z.A 2005. Fundamental investigations on the spark plasma sintering/synthesis process: I. Effect of dc pulsing on reactivity. Materials Science and Engineering A, vol. 394, no. 1-2. pp. 132-138.

Cheng, Z.G., Zhou, Q.Y., WAng, C.X., Li, Q.A., Wang, C., and FAng, Y. 2011. Toward intrinsic graphene surfaces: a systematic study on thermal annealing and wet-chemical treatment of $\mathrm{SiO}_{2}$-supported graphene devices. Nano Letters, vol. 11. pp. 767-771.

CHOA, Y-H., KAWAOKA, H., SEKIno, T., and NiIHARA, K. 1998. Microstructure and mechanical properties of oxide based nanocomposites fabricated by spark plasma sintering. Key Engineering Materials, vol. 136, no. 3. pp. 13-20.

Claussen, N., Steeb, J., and Pabst, R.F. 1977. Effect of induced microcracking on the fracture toughness of ceramics. Bulletin of the American Ceramic Society, vol. 56. pp. 559-562.

CLAussen, W. 1976. Fracture toughness of $\mathrm{Al}_{2} \mathrm{O}_{3}$ with an unstabilized $\mathrm{ZrO}_{2}$ dispersed phase. Journal of the American Ceramic Society, vol. 59, no. 1-2. pp. 49-51.

Claussen, W. and Ruhle, M. 1981 Advances in Ceramics Vol. 3, Science and Technology of Zirconia I. American Ceramic Society, Columbus, OH, USA p. 137.

Dusza, J., Morgiel, J., Duszova, A., Kvetkova, L., Nosko, M., Kun, P., and BALAZSI, C. 2012. Microstructure and fracture toughness of $\mathrm{Si}_{3} \mathrm{~N}_{4}+$ graphene platelet composites. Journal of the European Ceramic Society, vol. 32. pp. 3389-3397.

Elissalde, C., Maglione, M., and Estournes, C. 2007. Tailoring dielectric properties of multilayer composites using spark plasma sintering. Journal of the American Ceramic Society, vol. 90, no. 3. pp. 973-76.

Evans, A.G. 1984. Fracture in Ceramic Materials. Noyes, NJ, USA

Evans, A.G. and CANnon, R.M. 1986. Overview no. 48: toughening of brittle solids by martensitic transformations. Acta Metallurgica, vol. 34 . pp. $761-800$.

FANG, Z.Z. 2010. Sintering of Advanced Materials. Woodhead Publishing, Cambridge, UK.

GALUSEK, D., SEDLACEK, J., and RiedEL, R. 2007. $\mathrm{Al}_{2} \mathrm{O}_{3}-\mathrm{SiC}$ composites prepared by warm pressing and sintering of an organosilicon polymer-coated alumina powder. Journal of the European Ceramic Society, vol. 27, no. 6 . pp. 2385-2392.

GAo, L., Wang, H.Z., Hong, J.S., MiYamoto, H., and NishiKawa, Y. 1999a. SiC$\mathrm{ZrO}_{2}(3 \mathrm{Y}) \mathrm{Al}_{2} \mathrm{O}_{3}$ nano-composites superfast densified by spark plasma sintering. Nanostructured Materials, vol. 11, no. 1. pp. 43-49.

GAo, L., LI, J.G., Kusunose, T., and NiHARA, K. 2004. Preparation and properties of TiN-Si $\mathrm{N}_{3}$ composites. Journal of the European Ceramic Society, vol. 24, no. 2. pp. 381-386.

GaO, L., Hong, J.S., MiYamoto, H., MiYamoto, K., NishiKawa, Y., and Torre, S.D.D.L. 1999b. $\mathrm{SiC}_{-} \mathrm{ZrO}_{2}(3 \mathrm{Y})-\mathrm{Al}_{2} \mathrm{O}_{3}$ nanocomposites superfast densified by spark plasma sintering. Journal of the European Ceramic Society, vol. 19 , no. 5. pp. 609-613.

GeIM, A.K. and Novoselov, K.S. 2007. The rise of graphene. Nature Materials, vol. 6. pp. 183-191.

GolLA, B.R. and BASU, B. 2014. Comprehensive Hard Materials. Vol. 2. Elsevier. pp. 177-205.

Grasso, S., Yoshida, H., Porwal, H., and ReEce, M. 2013. Highly transparent aalumina obtained by low cost high pressure SPS. Ceramics International, vol. 39. pp. 3243-3248.

Grasso, S., SAKKA, Y., and MaizZA, G. 2009. Electric current activated/assisted sintering (ECAS): a review of patents 1906-2008. Science and Technology of Advanced Materials, vol. 10. pp. 1-24.

GuA, Y.W., KHoRA, K.A., and CHIEng, P. 2004. Bone-like apatite layer formation on hydroxyapatite prepared by spark plasma sintering (SPS). Biomaterials, vol. 25. pp. 4127-4134.

Guillon, O., Gonzalez-Julian, J., Dargatz, B., Kessel, T., Schierning, G., Räthel, J., and Herrmann, M. 2014. Field-assisted sintering technology/spark plasma sintering: mechanisms, materials, and technology developments. Advanced Engineering Materials, vol. 16. pp. 830-848.

HE, T., LI, J., WANG, L., ZHU, J., and JiAng, W. 2009. Preparation and consolidation of alumina/graphene composite powders. Materials Transanctions, vol. 50 , no. 4. pp. $749-751$.

Herrmann, M., Schuber, C., Rendtel, A., and Hubher, H. 1998. Silicon nitride/silicon carbide nanocomposite materials: II, Hot strength, creep, and oxidation resistance. Journal of the American Ceramic Society, vol. 81, no. 5. pp. $1095-1105$
Hirata, M., Gotou, T., Horiuchi, S., and Fuiwara, M. 2004. Thin-film particles of graphite oxide 1: High-yield synthesis and flexibility of the particles. Carbon, vol. 42, no. 14. pp. 2929-2937.

Holland, T.B., Anselmi-Tamburini, U., Quach, Tien, D.V., Tran, B., and MuKHERJEE, A.K. 2012. Effects of local Joule heating during the field assisted sintering of ionic ceramics. Journal of the European Ceramic Society, vol. 32, no. 14. pp. 3667-3674.

IIjMA, S. 1991. Helical microtubules of graphitic carbon. Nature, vol. 354 pp. 56-58.

InouE, K. 1966. Electric discharge sintering. US patent 3,241,956.

JANG, B.Z. and Zhamu, A. 2008. Processing of nanographene platelets (NGPS) and NGP nanocomposites: a review. Journal of Materials Science, vol. 43. pp. 5092-5101

Jiang, D., Hulbert, D.M., Kuntz, J.D., Anselmi-Tamburini, U., and Mukherjee, A.K. 2007. Spark plasma sintering: a high strain rate low temperature forming tool for ceramics. Materials Science and Engineering A, vol. 463. pp. 89-93.

KAWANO, S., TAKAHASHI, J., and SHIMADA, S. 2002. Highly electroconductive TiN/Si ${ }_{3} \mathrm{~N}_{4}$ composite ceramics fabricated by spark plasma sintering of $\mathrm{Si}_{3} \mathrm{~N}_{4}$ particles with a nano-sized TiN coating. Journal of Materials Chemistry, vol. 12. pp. 361-365.

KESSEL, H.U. and HenNICKE, J. 2007. Aspects concerning the super-fast sintering of powder metallic and ceramic materials. International Ceramic Review, vol. 56, no. 3. pp. 164-166.

KeSSEL, H.U., HenNiCKE, J., KIRCHNER, R., and KeSSEL, T. 2009. Rapid sintering of novel materials by FAST/SPS - further development to the point of an industrial production process with high cost efficiency. FCT Systeme $\mathrm{GmbH}$, Rauenstein, Germany. http://fctsysteme.de/download/20100225123420/FCT-Sintered-Materials.pdf

Khalit, K.A. 2012. Ceramic Materials: Progress in Modern Ceramics. InTech. pp. 65-82.

KuntZ, J.D., ZHAN, G.D., and MuKHARJEE, A.K. 2004. Improved fracture toughness in advanced nanocrystalline ceramic composites. MRS Proceedings, vol. 821.

KunTZ, J.D., WAN, J., ZhAN, G-D., and MUKHERJEE, A.K. 2002. Microstructure of alumina-niobium nanocomposites made by novel processing methods. Proceedings of the Second International Symposium on Ultrafine Grained Materials, 2002 TMS Spring Meeting, Seattle, WA, 17-21 Feburary. The Minerals, Metals and Materials Society, Warrendale, PA.

LANGE, F.F. 1982. Transformation toughening. Journal of Materials Science, vol. 17, no. 1. pp. 247-254.

LAwn, B.R. 1998. Fracture of Brittle Solids. Cambridge University Press, Cambridge, UK.

LiaO, L., Lin, Y.C., BAo, M.Q., CHENG, R., BAi, J.W., Liu, Y.A., Qu, Y.Q., WANG, K.L., HuAnG, Y., and DuAn, X.F. 2010. High-speed graphene transistors with a self-aligned nanowire gate. Nature, vol. 467 , no. 7313 . pp. 305-308.

LIU, J., YAN, H., and JIANG, K. 2013. Mechanical properties of graphene plateletreinforced alumina ceramic composites. Ceramics International, vol. 39. pp. 6215-6221.

Liu, J., YAn, H., ReEcE, M.J., and JiAnG, K. 2012. Toughening of zirconia/alumina composites by the addition of graphene platelets. Journal of the European Ceramic Society, vol. 32. pp. 4185-4193.

Liv, X., ZHou, D.M., and Hou, W.C. 2006. Transactions of Nonferrous Metals Society of China, vol. 16. pp. 5494-5497.

Maglia, F., Tredici, I.G., and Anselmi-Tamburini, U. 2013. Densification and properties of bulk nanocrystalline functional ceramics with grain size below 50nm. Journal of the European Ceramic Society, vol. 33, no. 6. pp. 1045-1066.

MAITRA, S. 2014. Nanoceramic matrix composites: types, processing and applications. Advances in Ceramic Matrix Composites. Low, I.M. (ed.). Woodhead Publishing. pp. 27-42. http://www.sciencedirect.com/ science/book/9780857091208.

McMEeKING, R.M. and Evans, A.G. 1982. Mechanics of transformationtoughening in brittle materials. Journal of the American Ceramic Society, vol. 65 , no. 6. pp. 242-246.

MuкHорADHYAY, A. and BASU, B. 2007. Consolidation-microstructure-property relationships in bulk nanoceramics and ceramic nanocomposites: a review. International Materials Reviews, vol. 52, no. 5. pp. 257-288.

MuniR, Z.A., QuAch, D.V., and OHYANAGI, M. 2012. Electric field and current effects on sintering. Sintering: Mechanisms of Convention Nanodensification and Field Assisted Processes. Castro, R. and van Benthem, K. (eds.). Springer, Berlin/Heidelberg. Ch.7, pp. 137-158. 


\section{Spark plasma sintering (SPS) — an advanced sintering technique}

Nieto, A., LahiRi, D., and Agarwal, A. 2012. Synthesis and properties of bulk graphene nanoplatelets consolidated by spark plasma sintering. Carbon, vol. 50, no. 11. pp. 4068-4077.

NiHARA, K. 1991. New design concept of structural ceramics - ceramic nanocomposites. Journal of Ceramic Society of Japan, vol. 99. p. 974-982.

NiHARA, K. and NAKAHIRA, A. 1991. Advanced Structural Inorganic Composites. Vincenzini, P. (ed.). Elsevier, New York. pp. 637-664.

Nilhara, K., Nakahira, A., Sakai, G., and Hirabayashi, M. 1989. Composites, Corrosion/Coating of Advanced Materials, vol. 4. Kimura, S., Kobayashi, A., Umekawa, S., Nii, K., Saito, S., and Yoshiura, M. (eds.). Materials Research Society, Pittsburgh, USA. p. 129.

NiIHARA, K. and SuZUKI, Y. 1999. Strong monolithic and composite $\mathrm{MoSi}_{2}$ materials by nanostructure design. Materials Science and Engineering $A$, vol. 261. pp. 6-15.

OMORI, M. 2000. Sintering, consolidation, reaction and crystal growth by the spark plasma system (SPS). Materials Science and Engineering $A$ vol. 287. pp. 183-188.

ORU, R., LicherI, R., LocCI, A.M., and CAO, G. 2009. Consolidation/synthesis of materials by electric current activated/assisted sintering. Materials Science and Engineering R: Reports, vol. 63, no. 4. pp. 127-287.

PARK, J.K., ChUnG, U.J., and KIM, D.Y. 2006. Application of spark plasma sintering for growing dense $\mathrm{Pb}\left(\mathrm{Mg}_{1 / 3} \mathrm{Nb}_{2 / 3}\right)_{3-35}$ mol\% $\mathrm{PbTiO}_{3}$ single crystal by solid-state crystal growth. Journal of Electroceramics, vol. 17. pp. 509-513.

PotTs, J.R., Dreyer, D.R., Bielawski, Ch.W., and Ruoff, R.S. 2011. Graphenebased polymer nanocomposites. Polymer, vol. 52. pp. 5-25.

RAJ, R., CoLogna, M., and Francis, J.S.C. 2011. Influence of externally imposed and internally generated electrical fields on grain growth, diffusional creep, sintering and related phenomena in ceramics. Journal of the American Ceramic Society, vol. 94, no. 7. pp. 1941-1965.

Rajeswari, K., Hareesh, U.S., Sbairi, R., ChaKravarty, D., and Johnson, R. 2010. Comparative evaluation of spark plasma (SPS), microwave (MWS), two stage sintering (TSS) and conventional sintering (CRH) on the densification and micro structural evolution of fully stabilized zirconia ceramics. Science of Sintering, vol. 42. pp. 259-267.

Recnik, A., Bruley, J., Mader, W., Kolar, D., and RÜHLE, M. 1994. Structural and spectroscopic investigation of (111) twins in barium titanate. Philosophical Magazine B, vol. 70, no. 5. pp. 1021-1034.

RITCHIE, R.O. 2011. The conflicts between strength and toughness. Nature Materials, vol. 10. pp. 817-822.

Ritchie, R.O., BuehleR, M.J., and Hansma, P. 2009. Plasticity and toughness in bone. Physics Today, vol. 62, no. 6. pp. 41-47.

Sahetat, J.P., Kulik, A.J., Bonard, J.M., Briggs, G.A.D., StockLi, T., Bonnamy, S., and ForRo, L. 1999. Elastic modulus of ordered and disordered multiwalled carbon nanotubes. Advanced Materials, vol. 11, no. 2. pp. 161-165.

Sciti, D., Vicens, J., AND Bellosi, A. 2002. Microstructure and properties of $\mathrm{Al}_{2} \mathrm{O}_{3}$-SiC nanocomposites. Journal of Materials Science, vol. 37. pp. 3747-3758.

SEKINo, T. and NiIHARA, K. 1995. Microstructural characteristics and mechanical properties for $\mathrm{Al}_{2} \mathrm{O}_{3}$ /metal nanocomposities. Nanostructural Materials, vol. 6, no. 5-8. pp. 663-666.

Selaho, T., NaKajima, T., Ueda, S., and Nimhara, K. 1997. Reduction and sintering of a nickel-dispersed-alumina composite and its properties. Journal of the American Ceramic Society, vol. 80, no. 5. pp. 1139-1148.

Sergueeva, A.V., Hulbert, D.M., Mara, N.A., and Mukharjee, A.K. 2009. Mechanical properties of nanocomposite materials. Nanostructructured Materials. Wilde, G. (ed.). Elsevier, New York. Ch. 3, pp. 127-171.

SHAPIRO, I.P., ToDD, R.I., and RoBERTS, S.G. 2009. Effects of $\mathrm{Y}_{2} \mathrm{O}_{3}$ additives and powder purity on the densification and grain boundary composition of $\mathrm{Al}_{2} \mathrm{O}_{3} / \mathrm{SiC}$ nano-composites. Journal of the European Ceramic Society, vol. 29, no. 10. pp. 1613-24.

SigL, L.S., MAKAGA, P.A., and DALGeISH, B.J. 1988. On the toughness of brittle materials reinforced with a ductile phase. Acta Metallurgica, vol. 36, no. 4. pp. 945-953.

Stankovich, S., Dikin, D.A., Dommelt, G.H.B., KohlhaAs, K.M., Zimney, E.J., Stach, E.A., Piner, R.D., Nguyen, S.T., and Ruoff, R.S. 2006. Graphenebased composite materials. Nature, vol. 442, pp. 282-286.

StERnitzKe, M. 1997. Review: Structural ceramic nanocomposites. Journal of the European Ceramic Society, vol. 17. pp. 1061-1082.

STERNitzKe, M. 1997. Structural ceramic nanocomposites. Journal of the European Ceramic Society, vol. 17. pp. 1061-1082

Suarez, M., Fernandez, A., Menendez, J.L., Torrecilles, R., Kessel, H.U., HenNicke, J., KIRChNER, R., and KeSSEL, T. 2013. Challenges and opportu- nities for spark plasma sintering: a key technology for a new generation of materials. InTech. pp. 319-338.

Suarez, M., Fernandez, A., Menendez, J.L. Torrecillas, R., Kessel, H.U., Hennicke, J., KIRchner, R., and KeSSEL, T. 2010. Challenges and opportunities for spark plasma sintering: a key technology for a new generation of materials. Sintering Applications. Ertu , B. (ed.). InTech. Ch. 13. pp. 319-342.

Tang, C.Y., Usкoкovic, P.S., Tsui, C.P., Veljonic, Di., Petrovic, R., and Janackovic, DJ. 2009. Influence of microstructure and phase composition on the nanoindentation characterization of bioceramic materials based on hydroxyapatite. Ceramics International, vol. 35, no. 6. pp. 2171-2178.

TAYA, M., Hayashi, S., KoBayashi, A.S., and Yoon, H.S. 1990. Toughening of a particulate-reinforced ceramic-matrix composite by thermal residual stress. Journal of the American Ceramic Society, vol. 73, no. 5. pp. 1382-1389.

ТокітA, M. 2013. Spark plasma sintering (SPS) method, systems, and applications. Handbook of Advanced Ceramics. Somiya, S. (ed.). Elsevier. pp. 1149-1177. http://www.gbv.de/dms/tib-ub-hannover/73334674x.pdf

Tomar, V. 2008. Analyses of the role of grain boundaries in mesoscale dynamic fracture resistance of $\mathrm{SiC}-\mathrm{Si}_{3} \mathrm{~N}_{4}$ intergranular nanocomposites. Engineering Fracture Mechanics, vol. 75. pp. 4501-4512.

UPADHYAYA, G.S. 2011. Future directions in sintering research. Science of Sintering, vol. 43. pp. 3-8.

Uraiwan, L-A., Matsunaga, T., Kobayashi, Y., Choi, S-M., and Awaj, H. 2005. Soaking method for fabrication of alumina-based nanocomposites. Ceramics International, vol. 31, no. 6. pp. 803-809.

Vameensel, K., Laptev, A., van der Biest, O., and Vleugels, J. 2007. The influence of percolation during pulsed electric current sintering of $\mathrm{ZrO}_{2}-$ TiN powder compacts with varying TiN content. Acta Materialia, vol. 55. pp. 1801-1811.

VARElA, J.A., WhitTemore, O.J., and Longo, E. 1990. Pore size evolution during sintering of ceramic oxides. Ceramics International, vol. 16, no. 3 . pp. 177-189.

Volceanov, E., Motoc, Ş., Abagiu, A.T., Volceanov, A., and Stoleriu, Ş. 2007. Influence of sintering environment on zirconia-metal carbides characteristics. Journal of the Europen Ceramic Society, vol. 27, no. 2-3. pp. 763-768.

WALKER, C.N., BoRSA, C.E., Todd, R.I., DARIDGE, R.W., and BRooK, R.J. 1994. Fabrication, characterisation and properties of alumina matrix nanocomposites. British Ceramic Proceedings, vol. 53. pp. 249-264.

WALKER, L.S., MarRotTo, V.R., RAFFice, M.A., KoratKar, N., and CoRRAL, E.L. 2011. Toughening in graphene ceramic composites. ACS Nano, vol. 5 , no. 4. pp. 3182-90.

WANG, J. and Stevens, R. 1989. Review zirconia-toughened alumina (ZTA) ceramics. Journal of Materials Science, vol. 24, no. 10. pp. 3421-3440.

Xu, Y., NAKAhiRA, A., and Nimhara, K. 1994. Characteristics of $\mathrm{Al}_{2} \mathrm{O}_{3}-\mathrm{SiC}$ nanocomposite prepared by sol-gel processing. Journal of Ceramic Society of Japan, vol. 102, no. 3. pp. 312-315.

Yamamoto, G., Shirasu, K., Hashida, T., Takagi, T., and Ruoff, R.D. 2011. Nanotube fracture during the failure of carbon nanotube/alumina composites. Carbon, vol. 49. pp. 3709-3716.

Yамамото, G., Omori, M., Hashida, T., and Kimura, H. 2008. A novel structure for carbon nanotube reinforced alumina composites with improved mechanical properties. Nanotechnology, vol. 19, no. 31. pp. 1-7.

Yoon, B.K., CHIN, E.Y., and KANG, S.J.L. 2008. Dedensification during sintering of $\mathrm{BaTiO}_{3}$ caused by the decomposition of residual $\mathrm{BaCO}_{3}$. Journal of the American Ceramic Society, vol. 91, no. 12. pp. 4121-4124.

Yoon, T., Shin, W.C., KIM, T.Y., Mun, J.H., KIm, T.S., and Cho, B.J. 2012. Direct measurement of adhesion energy of monolayer graphene as-grown on copper and its application to renewable transfer process. Nano Letters, vol. 12, no. 3. pp. 1448-1452.

Yu, M.F., LouRie, O., Moloni, K., Kelly, T.F., and Ruoff, R.S. 2000. Strength and breaking mechanism of multiwalled carbon nanotubes under tensile load. Science, vol. 287. pp. 637-640.

Zhan, G.D., KuntZ, J.D., WAN, J.L., and MuKhaRJEe, A.K. 2003. Single-wall carbon nanotubes as attractive toughening agents in alumina-based nanocomposites. Nature Materials, vol. 2. pp. 38-42.

ZhAN, G-D., KunTZ, J.D., WAN, J., and MuKHERJEe, A.K. 2003. Single-wall carbon nanotubes as attractive toughening agents in alumina-based nanocomposites. Nature Materials, vol. 2. pp. 38-42.

Zhan, G-D., LAI, T-R., Shi, J-L., Yen, T-S., Zhou, Y., and Zhang, Y-Z. 1996. Microstructure and mechanical properties of yttria-stabilized tetragonal zirconia polycrystals containing dispersed TiC particles. Journal of Materials Science, vol. 31, no. 11. pp. 2903-2907. 